\title{
A Unified Theory of Neutral Grounding Methods in Power Distribution Systems
}

\author{
Yubo Wang (Wayne Wong) \\ Independent Researcher, Shanghai, China
}

\begin{abstract}
The neutral grounding in power distribution system is an important aspect for earth fault protection, power supply reliability and safety. The performance varies greatly with different grounding methods by which the protective effect presents various results with identical impedance of single phase earth fault. Arguments for better neutral protection has been continued in the distribution field for decades, unfortunately, there is still not a conclusion due to the discussions lacking of a unified modelling or theory of neutral groundings. Thus, the understanding of neutral grounding in most countries differs considerably. Surprisingly solid/isolated grounding in some countries is still considered as a mainstream grounding method in today's distribution grids, likewise, some utilities are still persisting on adopting resistance grounding to pursue to improve detection sensitivity and reliability, and so on. In this paper, a unified theory is proposed to shed light on the neutral groundings within one unprecedented modelling by which neutral groundings can be compared and evaluated quantitatively for the first time in the history of power distribution field perhaps.
\end{abstract}

Keywords: Neutral Groundings, Earth Fault, Distribution Grid, Sensitivity, Reliability

\section{Background}

The core of neutral point grounded in distribution systems is well known for earth fault protection. The existing grounding methods encompassing solid/isolated grounding, ungrounded, resistance grounding and resonant grounding are widely utilized in the world for detecting the predominating earth faults, however, it varies much in different countries, for instance, solid grounding used in North America, resistance grounding in Australia and Turkey, ungrounded in most grids in China, and resonant grounding in Germany, Nordic countries, Russia etc. In China, nearly 20\% distribution grids now are resonance grounded systems, the number still increasing.

Arguments and analysis for the pros and cons of different grounding methods can be found in many professional articles, however, the essential correlation of the grounding methods is barely picked to explain in the past except that all of them related to neutral point, instead, they are often introduced and analyzed separately to conclude characters of each neutral grounding but without an unified benchmark for all.

Is there a unified theory to explain them all universally and mathematically?

The answer is no before this work, a unified theory with three mathematical equations 
is proposed in the paper for calculating and evaluating all the neutral groundings universally. The aim of this work is to guide global utilities to estimate and recognize the grounding protections and select the most efficient one to be installed to highly improve the SAIDI and SAIFI figures, i.e. reducing power outage, human safety risks and fire hazards.

\section{Introduction}

Earth fault in power distribution systems is a lasting topic in global distribution conferences and forums, Although new ideas affiliating the mainstream grounding methods were proposed to offer more options for enriching toolbox of utilities, it's not easy to absorb efficiently if the mainstream neutral groundings are not well understood and deeply combed out the core correlation between them. This seminal work would creat a brand new perspective to re-examine traditional views of grounding protection. As known, Earth fault is a majority of electric faults in power systems, statistically more than $80 \%$ electrical fault is earth fault, it could be thought that if the earth fault problems mostly controlled, the power reliability and safety consequently will be dramatically improved. The hardship of earth fault detection is normally considered that the sensitivity of protection is not high enough, in the case, detection sensitivity basically determines whether the protection can be triggered to alarm in order to fast compensate or isolate the fault avoiding massive power outages.

Especially, the world is stepping into smart grid era, distribution networks will be more complex due to distributed Energy Resources(DERs) and Storage Energy Devices connected in the grids, a highly reliable protection is never important like today. Due to such earth fault problems, the monetary loss for governments, utilities, firms, hightech factories and residents can be countless and the influence to environment could be devastating. In 2009, the "Black Saturday" bushfire caused by powerline failure fault killed hundreds of people and burned thousands of residential houses and farms in Victoria area[1], which resulted in thousands of millions USD loss. Later on, the government put plenty of investment on the fire investigation and turned out the high impedance earth fault blinded the resistance grounding protection, the faulty line can't be tripped due to the fault current too small to be detected by the protection. In 2019, hazardous wild fire in California preliminarily was investigated and pointed to a transmission line contacting tree branches [2], thus the arcing fault igniting the trees or vegetations, perhaps due to high impedance fault producing not enough current to lead the protection to de-energize the faulty line.

Imagining that a neutral protection with low sensitivity, when there is an earth fault occurring in somewhere of the power lines, the protection can't "feel" it which means no fault alarm triggered to warn operators and it seems that the grid keeps working in normal operation because customers will be not disturbed during single phase earth fault. In fact, there would strike very dangerous arcing at fault which may put human lives in risk and cause fire as well.

This paper presents and outlines the fundamental influence factors of sensitivity of 
different neutral grounding systems and provide a benchmark to evaluate and calculate the relevant quantitative figures of the neutral grounding methods for the first time in the field perhaps. The author hope that the following presents a guidance to engineers, managers, firms and utility organizations etc. to yield returns from the pioneering efforts on the distribution field to efficient protection strategies and commercial solutions.

\section{Origin of The Study}

The unified theory starts from the individual research on resonance grounded system, i.e. the neutral grounded via Petersen coil. In China, there is a lasting debate between low resistance grounding and Petersen coil grounding, one claimed that resistance grounding is simpler and more reliable especially in cable systems or even the mixed, since most earth faults in cable system finally would be a permanent fault, therefore tripping is a whatsoever choice, one argued that resistance grounding due to tripping the line during transient earth faults will reduce power supply reliability, moreover, the overcurrent protection probably doesn't work once the fault impedance over $150 \mathrm{Ohms}$ in $10 \mathrm{kV}$ grids. However, besides the major ungrounded systems, State Grid stipulates Petersen coil used in the $10 \mathrm{kV}$ grids with no more than 150A capacitive current[3], and resistance grounding in cable systems or the grids with the capacitive current exceeding $150 \mathrm{~A}[3]$. In technical view, the sensitivity of this two protections varies, many previous researches indicate that Petersen coil can detect higher fault impedance than resistance grounding and would not impact customers during single phase earth fault before the fault isolated. Of what really drew the author's attention is the phenomena of discrepant sensitivities of which both connected to the same neutral point, what's the principle that results in the difference among those neutral groundings including solid grounding and ungrounded systems. Is that possible to derive a mathematical modelling to explain all of them. Plenty of questions give rise to the author's interests to study it.

In tap changer Petersen coil grounded system in China, an extra resistor in series connecting between the coil and earth potential by which increases the system damping ratio to restrict the neutral overvoltage during normal operation. As known, the neutral displacement is determined by detuning(v), damping(d) and dissymmetry(k), as:

$$
u_{e n}(\%)=\frac{k}{\sqrt{v^{2}+d^{2}}}
$$

Given $v$ and $k$, to enlarge $d$ is the way to restrict neutral voltage in normal operation. But higher damping gives higher active current in zero sequence, meanwhile, high damping also can reduce detecting sensitivity.

Regarding the special design of the extra resistor, assuming that detuning is adjusted at maximum position of under-compensation, i.e. $\mathrm{v}=-100 \%$, what a resonant grounding system convert into. Surprisingly, it changes to resistance grounding system physically due to coil taps not connected in the circuit but resistor only. The conversion process can be seen apparently in below diagrams. 


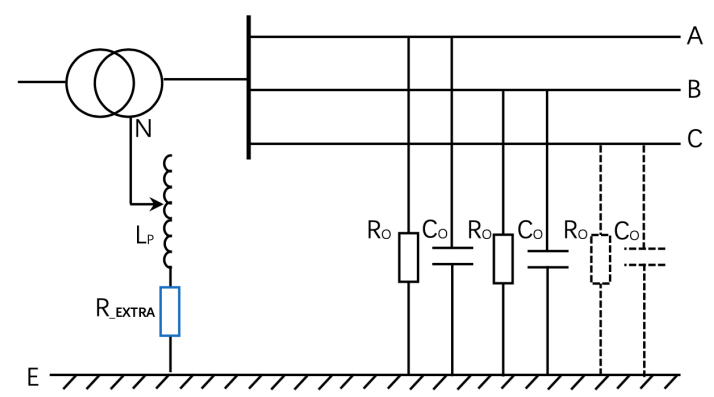

Figure 1: Petersen coil grounded system with extra resistor
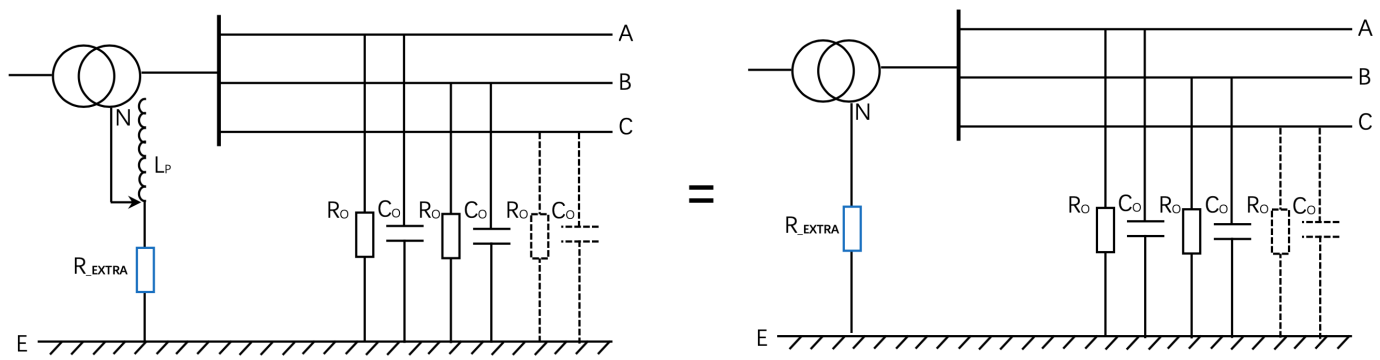

Figure 2: Petersen coil grounding converted to resistance grounding by detuning at $-100 \%$

In 2016, State Grid Henan Electric Power Research Institute organized primary fault tests, including simulation of bolted single phase earth fault(fault impedance close to zero) in $10 \mathrm{kV}$ resonance grounded system, it was observed that neutral voltage displaced $100 \%$ to phase voltage level whatever the detuning set, the neutral voltage always maintains $100 \%$ and the fault current in different detuning(v) differs, which can be explained that fault current is composed of reactive and active components[4], the former one is either capacitive current or inductive current depending on the detuning setting, the latter one is active current up to system damping ratio. The three phases are supposed to be symmetrical, then it can be known that:

\section{Detuning:}

$$
v=\frac{B_{O}-3 B}{3 B}=\frac{\left(B_{O}-3 B\right) \cdot U_{E N}}{3 B \cdot U_{E N}}=\frac{I_{L}-I_{C}}{I_{C}}
$$

Where, $B_{0}$ is the susceptance between neutral point to earth.

$3 \mathrm{~B}$ is the susceptance of three-phase lines to earth.

$U_{E N}$ is neutral voltage that equals to value of phase voltage $U_{p h}$.

\section{Damping:}

$$
d=\frac{G_{O}+3 G}{3 B}=\frac{\left(G_{O}+3 G\right) \cdot U_{E N}}{3 B \cdot U_{E N}}=\frac{I_{r}}{I_{C}}
$$

Where, Go is the conductance between neutral point to earth.

$3 \mathrm{G}$ is the conductance of three-phase lines to earth. 
Therefore, the reactive and active current in bolted earth fault can be calculated with:

\section{Reactive Current:}

$$
I_{C-L}=\left|I_{L}-I_{C}\right|=|v| \cdot I_{C}
$$

\section{Active Current:}

$$
I_{r}=d \cdot I_{C}
$$

The total of zero sequence current can be calculated with the sum of reactive current and active current.

$$
I_{N}=\sqrt{\left(|v| \cdot I_{C}\right)^{2}+\left(d \cdot I_{C}\right)^{2}}=I_{C} \cdot \sqrt{v^{2}+d^{2}}
$$

The simulating bolted fault $\left(\mathrm{R}_{\mathrm{f}}=0\right)$ test in HEPRI showed the $100 \%$ neutral voltage was dropped across the integral zero sequence impedance $\left(\mathrm{Z}_{\mathrm{O}_{-} \text {int }}\right)$ as shown in figure 3 below.

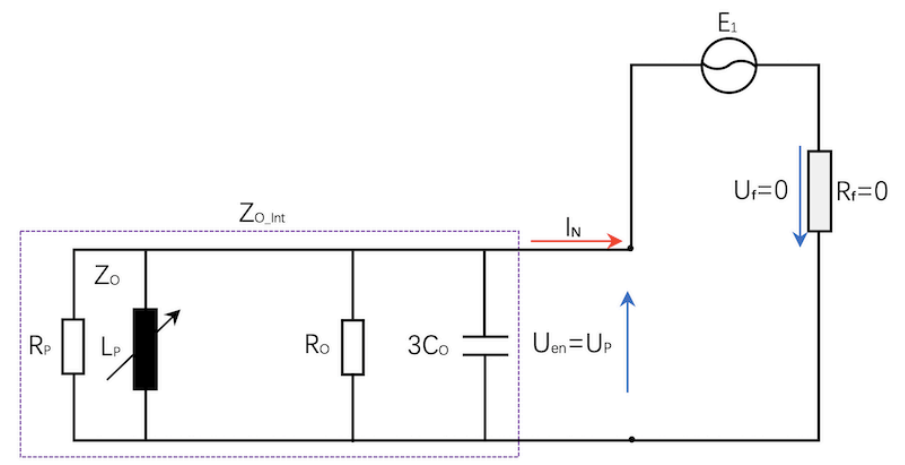

Figure 3: Equivalent zero sequence with Petersen coil grounded system

Thus, the $\mathrm{Z}_{\mathrm{O} \_ \text {int }}$ can be calculated as per Ohm's law,

$$
Z_{O_{-} i n t}=\frac{U_{E N}}{I_{N}}
$$

$\mathrm{Z}_{\mathrm{O} \text { int }}$ stands for the integral zero sequence impedance which should maintain the same value with following earth fault before any change of the system, i.e. damping, detuning, capacitive current etc.

At the same working conditions, assumed that an earth fault with some impedance $\left(\mathrm{R}_{\mathrm{f}}\right.$ $\neq 0$ ) that depends on the conducting surface, it can be easily known the total impedance of the zero sequence is:

$$
Z_{O \_t o t a l}=Z_{O \_ \text {int }}+R_{f}
$$

Due to neutral voltage divided by two parts of the impedance, neutral displacement and fault current can be calculated.

Neutral displacement:

$$
u_{e n}(\%)=\frac{Z_{O \_ \text {int }}}{Z_{O \_ \text {int }}+R_{f}}
$$


Zero sequence current:

$$
I_{N}=I_{f}=\frac{U_{e n}}{Z_{O_{-} i n t}}
$$

Where, $U_{e n}$ is the actual neutral voltage due to earth fault.

If the $\mathrm{R}_{\mathrm{f}}$ value increases, the $\mathrm{u}_{\mathrm{en}}(\%)$ and fault current $\mathrm{I}_{\mathrm{f}}$ will decline accordingly, but if the value of $Z_{o}$ int is also magnified from zero approaching to infinity, how $u_{\mathrm{en}}(\%)$ will change with different fault impedances $\left(\mathrm{R}_{\mathrm{f}}\right)$. The chart 1 is the relations between neutral displacement and zero sequence impedance under fault impedance from $0 \mathrm{Ohm}$ to $50 \mathrm{kOhm}$.

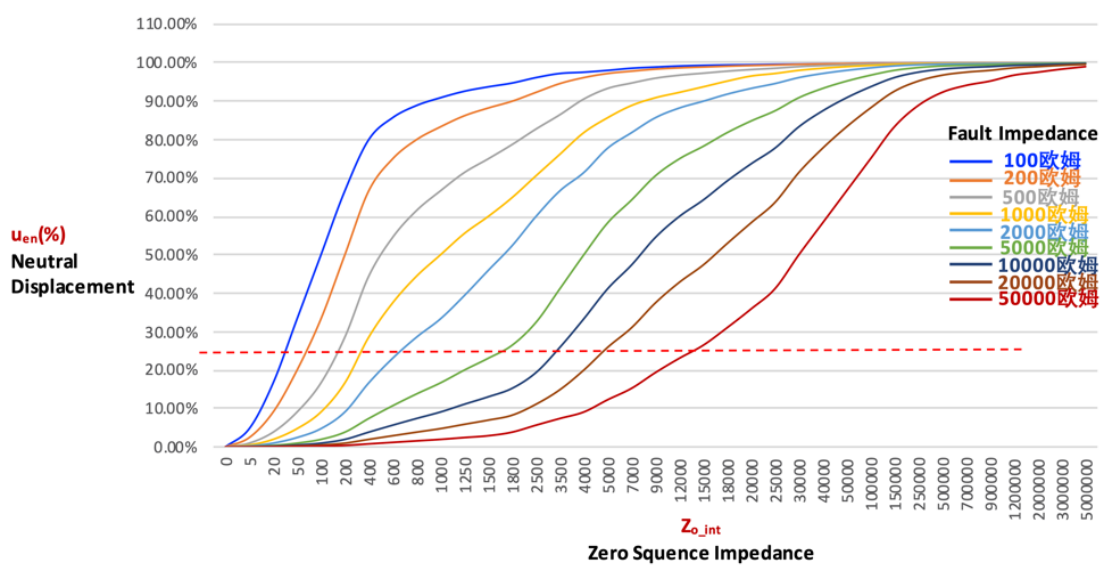

Chart 1: Correlations of neutral displacement and zero sequence impedance under different fault impedance

Apparently, when $\mathrm{Z}_{\mathrm{o}_{-} \text {int }}$ is large enough, the neutral voltage will always maintain $100 \%$ displacement during any fault impedances, even $50 \mathrm{kOhm}$ or higher impedance fault. In this case, neutral protections can easily be triggered with the fully displaced neutral voltage, which is the core of detecting sensitivity. The question now is how to enlarge the $Z_{o_{-} \text {int }}$ value. In LRC circuit, only if the current by whatever measures is eliminated or compensated to zero, an impedance across voltage without current flow is infinite as per Ohm's law.

$$
u(\%)=\lim _{Z_{o_{-} \text {int } \rightarrow \infty}} \frac{Z_{O_{-} \text {int }}}{\left(Z_{O_{-} \text {int }}+R_{f}\right)}=\lim _{Z_{o_{-} \text {int } \rightarrow \infty}} \frac{1}{\left(1+\frac{R_{f}}{Z_{o_{-} \text {int }}}\right)}=100 \%
$$

The limiting eq.(10) indicates that only if the $Z_{o_{-} \text {int }}$ to be infinite, $R_{f}$ will be no longer an influence factor to neutral displacement, which requires to eliminate the zero sequence current equivalent to the value of fault current with bolted earth fault, it's been known that the current is determined by detuning, damping and capacitive quantity, i.e. reactive current and active current. Although the detuning is a specific term for grid grounded via Petersen coil, it's also possible to convert any other neutral grounding systems to equivalent resonant grounding with a special setting of detuning as below diagrams shown. 


\section{New Modelling of System Groundings}

\subsection{Solidly/Isolated Grounded System}

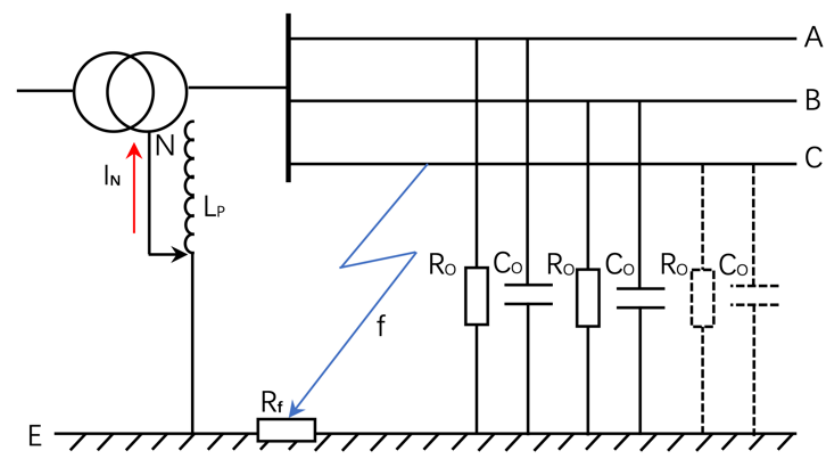

Figure 4: Earth fault in solidly/isolated grounded system $(v=-100 \%)$

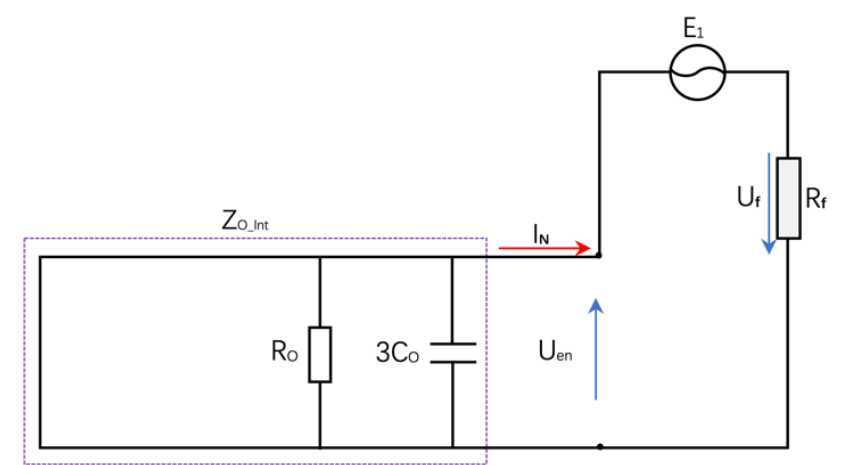

Figure 5: Equivalent zero sequence with solidly/isolated grounded system

The conversion from solid grounding to resonant grounding is by just adjusting the detuning to $-100 \%$, i.e. $\mathrm{I}_{\mathrm{L}}=0, \mathrm{v}=-100 \%$, no coil taps connected in the grid, although it looks Petersen coil grounding, essentially it's still solid grounding. By the modelling, the key parameters $\mathrm{v}$ and $\mathrm{d}$ can be calculated by using eq.(1) and (2) as:

Detuning: $v=-100 \%$

Damping: $d=d_{o}+d_{r}$

Where, $d_{0}$ is the normal damping mainly determined by the three-phase circuits.

Normally damping $d_{o}$ is $2-6 \%$ in overheads system, $1-5 \%$ in cable system. Assuming a resistor $\mathrm{R}$ connected between neutral and earth in series, the extra damping $d_{r}$ has to be considered. In solidly grounded system, the resistance between neutral and ground is zero, but the damping $\mathrm{d}_{\mathrm{r}}$ still can be calculated with the definition of damping as per eq.(2).

$$
d_{r}=\frac{G_{O}}{w c}=\frac{1}{R \cdot w c}=\frac{U_{E N}}{R \cdot\left(U_{E N} \cdot w c\right)}=\frac{U_{E N}}{R \cdot I_{C}}
$$

Due to $R=0$, the result of $d_{r}$ in eq.(11) is approaching infinity.

Therefore, $\mathrm{d}_{\mathrm{N}} \mathrm{d}_{\mathrm{o}}+\mathrm{d}_{\mathrm{r}}=\infty$

With a bolted earth fault $\left(\mathrm{R}_{\mathrm{f}}=0\right)$, by using the eq.(5), the fault current can be calauted: 


$$
I_{f}=I_{N}=I_{C} \cdot \sqrt{v^{2}+d^{2}}=\infty
$$

Since the neutral is grounded to earth potential, $\mathrm{u}_{\mathrm{en}}(\%)=0$.

The equivalent zero sequence impedance $\mathrm{Z}_{\mathrm{O}_{-} \text {int }}$ as in figure 5 can be calculated:

$$
Z_{O_{-} i n t}=\frac{U_{e n}}{I_{N}}=0
$$

Where, $\mathrm{Uen}_{\mathrm{en}}=\mathrm{u}_{\mathrm{en}}(\%) * \mathrm{U}_{\mathrm{EN}}$

Typically, the bolted earth fault turns out a single phase short circuit fault, the current can be infinite theoretically if there is an ideal source without any internal impedance. Practically, the secondary winding of power transformer and conductors exist certain impedance, therefore the current would not be really approaching infinite, for a single phase to ground short circuit fault, the current could be very high in kilo amperes.

In fact, earth fault in real grids is barely a bolted fault, more often than not there is some impedance at fault, $R_{f}$ will take effect to be dropped across voltage as seen in figure 5 .

So that, the total impedance of the zero sequence circuit now is:

$$
Z_{O_{-} t o t a l}=Z_{O_{-} i n t}+R_{f}=0+R_{f}=R_{f}
$$

Therefore, the fault current can be calculated:

$$
I_{f}=\frac{U_{E N}}{Z_{O_{-} \text {total }}}=\frac{U_{E N}}{R_{f}}
$$

Neutral voltage is entirely across the fault impedance Rf. The fault current is now fully determined by fault impedance in solidly/isolated grounded systems.

Still, neutral displacement $\mathrm{u}_{\mathrm{en}}(\%)$ close to earth potential.

\subsection{Resistance Grounded System}

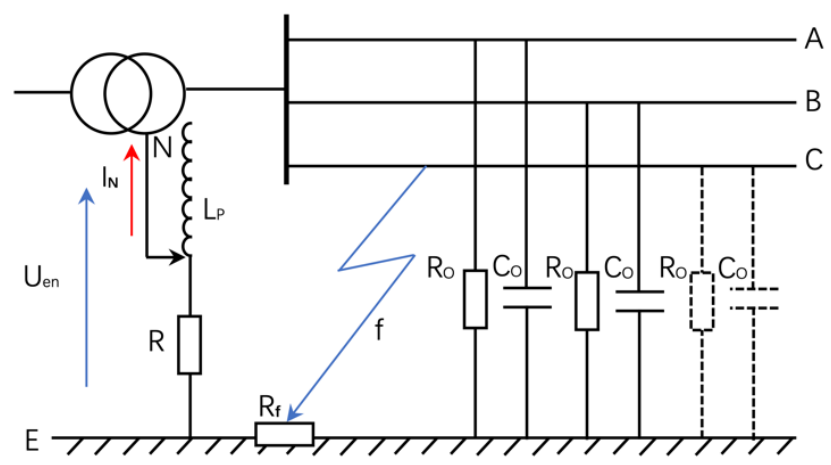

Figure 6: Earth fault in resistance grounded system $(\mathrm{v}=-100 \%)$ 


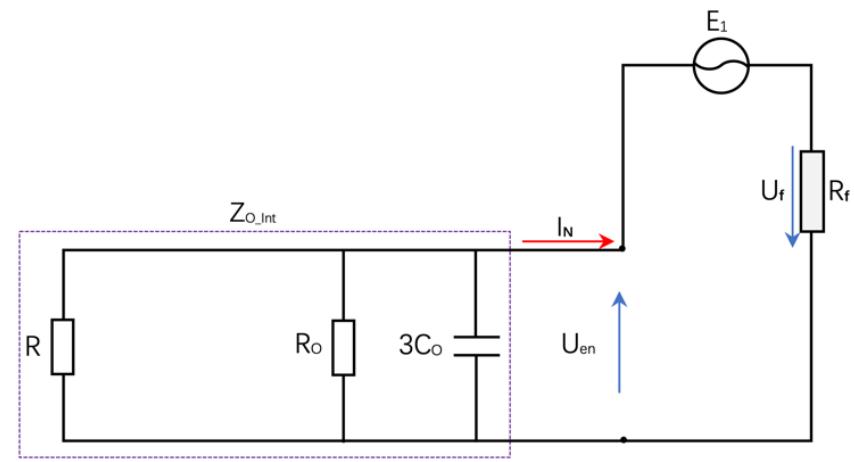

Figure 7: Equivalent zero sequence with resistance grounded system

In the similar manner, it can be known detuning $\mathrm{v}$ and damping $\mathrm{d}$ in resistance grounded system as figure 6 .

Detuning: $\mathrm{v}=-100 \%$

Damping: $d=d_{0}+d_{r}$

Normally the earthing resistor in low resistance grounded system in State Grid often is selected either $16 \mathrm{Ohm}$ or $40 \mathrm{Ohm}$, the latter one would be the most common value.

If $\mathrm{R}=40 \mathrm{Ohm}$, the damping $\mathrm{d}_{\mathrm{r}}$ can be calculated as per eq.(2)

$$
d r=\frac{G_{O}}{w c}=\frac{G_{O} \cdot U_{E N}}{w c \cdot U_{E N}}=\frac{U_{E N}}{R \cdot I c}
$$

In a $10 \mathrm{kV}$ grid with capacitive current $\mathrm{I}_{\mathrm{C}}=100 \mathrm{~A}, \mathrm{~d}_{\mathrm{r}}$ can be calculated by using eq.(15):

$$
d_{r}=\frac{10000}{\sqrt{3} \times 40 \times 100}=1.44
$$

Therefore,

$$
d=d_{o}+d_{r}=d_{o}+1.44
$$

With a bolted earth fault $\left(\mathrm{R}_{\mathrm{f}}=0\right), \mathrm{u}_{\mathrm{en}}(\%)$ and $\mathrm{I}_{\mathrm{f}}$ can be calculated by using eq.(5):

$$
\begin{aligned}
& u_{e n}(\%)=\frac{Z_{O_{\_} i n t}}{Z_{O_{-} i n t}+0}=100 \% \\
& I_{f}=I_{N}=I_{C} \cdot \sqrt{v^{2}+d^{2}}=100 \sqrt{1+\left(d_{o}+1.44\right)^{2}}
\end{aligned}
$$

Where, $\mathrm{d}_{\mathrm{o}}$ is normally between $1 \%-6 \%$ depending on the network size.

So that,

$$
Z_{O \_ \text {int }}=\frac{U_{E N}}{I_{N}}=\frac{10000}{\sqrt{3} \times 100 \times \sqrt{1+\left(d_{o}+1.44\right)^{2}}}
$$

When $\mathrm{R}_{\mathrm{f}} \neq 0$, the fault impedance has to be considered, $\mathrm{u}_{\mathrm{en}}(\%)$ and $\mathrm{I}_{\mathrm{f}}$ now is:

$$
u_{e n}(\%)=\frac{Z_{O_{-} i n t}}{Z_{O_{-} i n t}+R_{f}}<100 \%
$$


The bigger $\mathrm{R}_{\mathrm{f}}$, the less neutral voltage shifting.

And similarly, fault current can be calculated.

$$
I_{f}=I_{N}=\frac{U_{e n}}{Z_{O_{-} i n t}}
$$

In high resistance grounding system, the value of earthing resistor could be selected from hundreds to thousands Ohms. If a neutral resistor is valued $\mathrm{R}=300 \mathrm{Ohm}$ in a $10 \mathrm{kV}$ grid with 100A capacitive current. By using eq.(15):

$$
d_{r}=\frac{10000}{\sqrt{3} \times 300 \times 100}=0.19
$$

Therefore,

$$
d=d_{o}+0.19
$$

Similarly, with a bolted earth fault $\left(\mathrm{R}_{\mathrm{f}}=0\right), \mathrm{u}_{\mathrm{en}}(\%)$ and $\mathrm{I}_{\mathrm{f}}$ can be calculated as:

$$
\begin{aligned}
& u_{\text {en }}(\%)=\frac{Z_{O_{-} i n t}}{Z_{O_{-i n t}}+0}=100 \% \\
& I_{f}=I_{N}=I_{C} \cdot \sqrt{v^{2}+d^{2}}=100 \sqrt{1+\left(d_{o}+0.19\right)^{2}}
\end{aligned}
$$

Therefore,

$$
Z_{O_{-i n t}}=\frac{U_{E N}}{I_{N}}=\frac{10000}{\sqrt{3} \times 100 \times \sqrt{1+\left(d_{o}+0.19\right)^{2}}}
$$

Likewise, when fault impedance is not zero, $\mathrm{u}_{\mathrm{en}}(\%)$ and $\mathrm{I}_{\mathrm{f}}$ :

$$
\begin{aligned}
& u_{e n}(\%)=\frac{Z_{O_{-i n t}}}{Z_{O_{-} i n t}+R_{f}}<100 \% \\
& I_{f}=I_{N}=\frac{U_{\text {en }}}{Z_{O_{-i n t}}}
\end{aligned}
$$

\subsection{Ungrounded or Isolated Grounding}

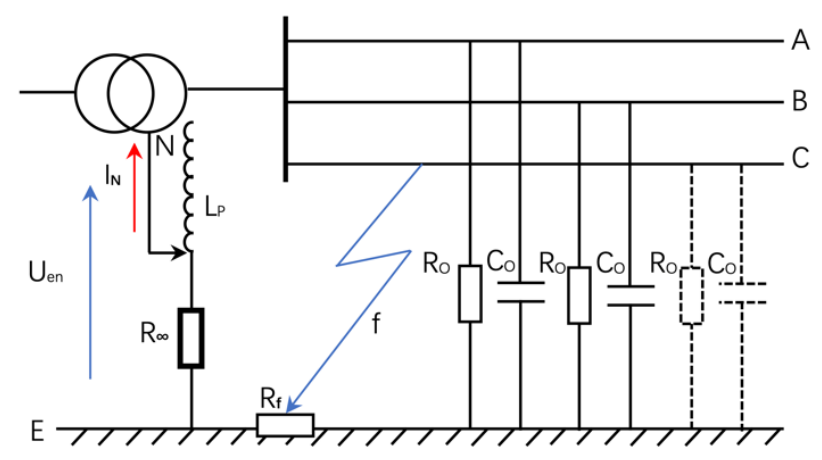

Figure 8: Earth fault in neutral ungrounded system $(v=-100 \%)$ 


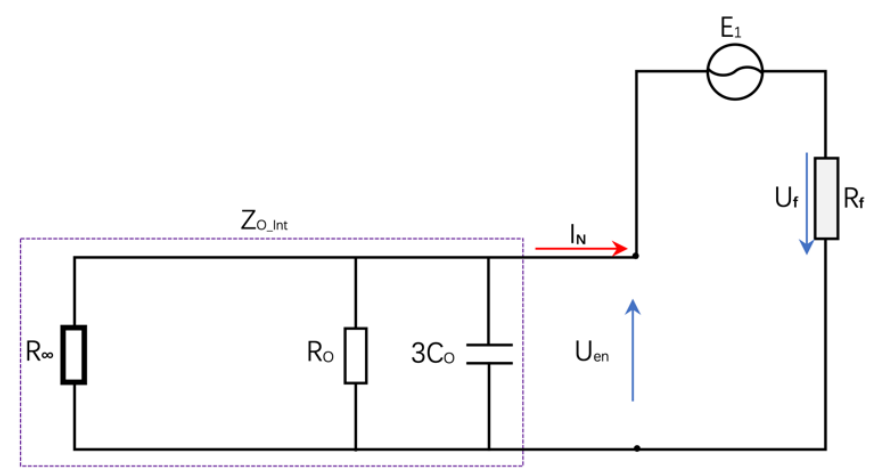

Figure 9: Equivalent zero sequence with ungrounded $\operatorname{system}(\mathrm{R}=\infty)$

The ungrounded system also can be converted to Petersen coil grounding with $v=-100 \%$. Considering there is no connection between neutral to earth, but it still can be equivalent to an infinite value of resistor $(R=\infty)$ connected between as figure 8 shown. so that, $d_{r}$ eventually can be calculated as below.

$$
d_{r}=\frac{G_{O} \cdot U_{E N}}{w c \cdot U_{E N}}=\frac{U_{E N}}{R \cdot I_{C}}=0
$$

Therefore,

$$
d=d_{o}+d_{r}=d_{o}+0=d_{o}
$$

With a bolted earth fault $\left(\mathrm{R}_{\mathrm{f}}=0\right)$ in a $10 \mathrm{kV}$ grid, $\mathrm{I}_{\mathrm{C}}=100 \mathrm{~A}, \mathrm{~d}_{\mathrm{o}}=4 \%$, the fault current is:

$$
I_{f}=I_{N}=I_{C} \cdot \sqrt{v^{2}+d^{2}}=100 \times \sqrt{1+0.04^{2}}=100 \mathrm{~A}
$$

It can be found that the value of fault current $\left(\mathrm{I}_{\mathrm{f}}\right)$ is basically as the same as the capacitive current which can be concluded that the fault current is composed of capacitive current only in ungrounded system during a bolted earth fault.

Due to $\mathrm{R}_{\mathrm{f}}=0$, there is no voltage across it, therefore the neutral displacement $\mathrm{u}_{\text {en }}(\%)$ will be $100 \%$.

The zero sequence impedance $\mathrm{Z}_{\mathrm{O} \_ \text {int }}$ can be calculated similarly in figure 9 .

$$
Z_{O_{-} i n t}=\frac{U e n}{I_{N}}=\frac{10000}{\sqrt{3} \times 100}=57.7 \Omega
$$

At the same grid condition, assumed that an earth fault with fault impedance $\mathrm{R}_{\mathrm{f}}=1000 \Omega$, $\mathrm{u}_{\mathrm{en}}(\%)$ and $\mathrm{I}_{\mathrm{f}}$ can be calculated as below.

$$
\begin{gathered}
u_{e n}(\%)=\frac{Z_{O_{\_} i n t}}{Z_{O_{-} i n t}+R_{f}}=\frac{57.7}{57.7+1000}=5.5 \% \\
I_{f}=I_{N}=\frac{U_{\text {en }}}{Z_{O_{-} i n t}}=\frac{5.5 \% \times 10000}{\sqrt{3} \times 57.7}=5.5 \mathrm{~A}
\end{gathered}
$$

That's very minor current for overcurrent protection in ungrounded system, the 
current most likely couldn't be detected due to smaller than the threshold.

Therefore, State Grid requires that ungrounded method is only allowed to be applied in grids with capacitive current less than 10A[3], even if a bolted fault, the current less than 10A would not produce hazardous arcing at fault.

\subsection{Resonance Grounded System(Petersen coil)}

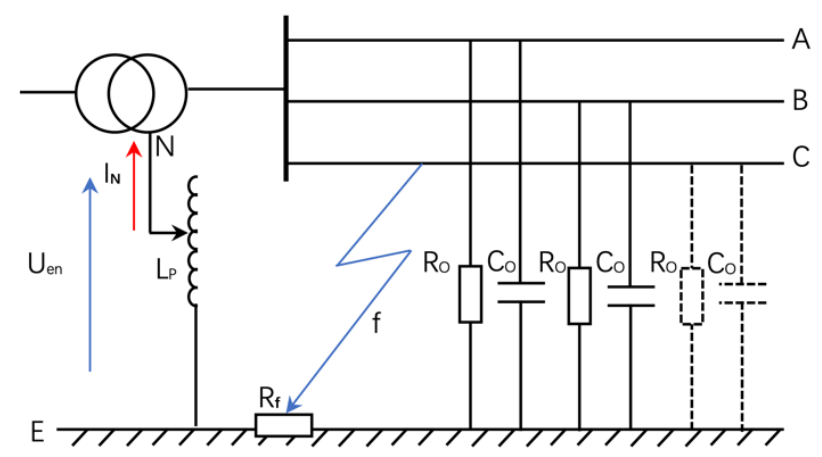

Figure 10: Earth fault in resonance grounded system(Petersen coil)

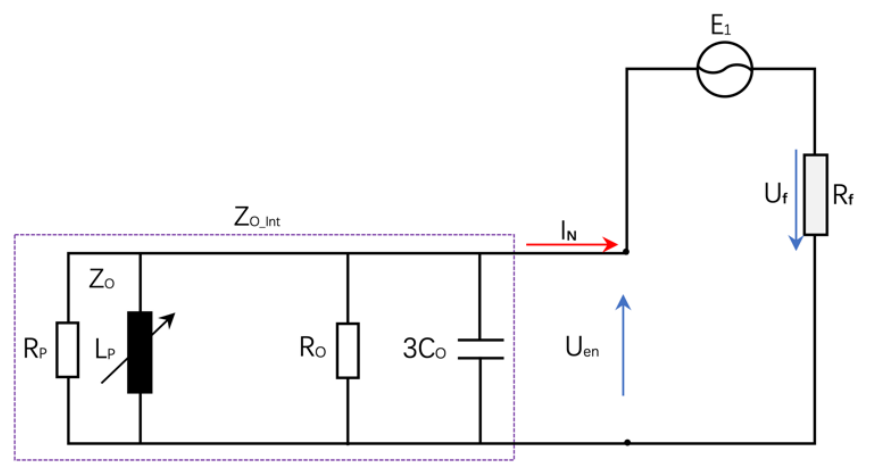

Figure 11: Equivalent zero sequence with resonance grounded system

The detuning of tap changer arc suppression coil in China normally is set between 5\% to $10 \%$ at slightly over-compensation position.

As above mentioned, an extra resistor is normally required by State Grid to connected between neutral to earth for limiting resonance over-voltage. Many years' engineering experience tells that the extra resistor can bring up the damping ratio from the normal level $1 \% \sim 6 \%$ to $30 \%$ or more, which could extremely reduce the sensitivity of Petersen coil for high impedance fault detection.

In this paper, considering that the special design of extra resistor doesn't stand for the most common applications in the world, therefore, the modelling as figure 10 is not including extra resistor, but Petersen coil only.

Assumed that a $10 \mathrm{kV}$ grid, $\mathrm{I}_{\mathrm{C}}=100 \mathrm{~A}, \mathrm{v}=5 \%, \mathrm{~d}=\mathrm{d}_{\mathrm{o}}=4 \%$, with a bolted earth fault, then fault current can be calculated below:

$$
I_{f}=I_{N}=I_{C} \cdot \sqrt{v^{2}+d^{2}}=100 \times \sqrt{0.05^{2}+0.04^{2}}=6.4 \mathrm{~A}
$$

Due to $\mathrm{R}_{\mathrm{f}}=0$, $\mathrm{u}_{\mathrm{en}}(\%)$ close to $100 \%$ displacement, 
Therefore,

$$
Z_{O_{-} i n t}=\frac{U_{e n}}{I_{N}}=\frac{10000}{\sqrt{3} \times 6.4}=902 \Omega
$$

Whatever detuning is positioned during bolted earth fault, the neutral displacement always is presented $100 \%$. But the big detuning can result in high zero sequence current, then zero sequence impedance is weakened with low neutral displacement.

In recent years, high impedance earth fault has been discussed widely over the world. Relying on traditional over-current protection to address such high impedance fault becomes more and more frustrating[5], especially fire hazards caused by treetouching and broken line fallen on ground or inflammable objects, the fault impedance is depending on where the fault occurs or where the broken line fallen, in which produce fault current that can differentiate a lot.

For a resonance grounded system, assuming a high impedance fault with some kOhms in grid, neutral displacement shall be exceeding the 3Uo threshold for fault detection which is normally determined by dissymmetry(k) and damping (d), neutral voltage at resonance point during normal operation can be calculated with:

$$
u_{\text {en.max }}(\%)=\frac{k}{d}
$$

The threshold value should be higher than this resonance value $U_{\text {en.max }}$ in order to avoid frequent false alarms during normal operation.

With a high impedance fault $\mathrm{R}_{\mathrm{f}}=3000 \Omega$, the neutral displacement:

$$
u_{e n}(\%)=\frac{Z_{O \_ \text {int }}}{Z_{O_{-i n t}}+R_{f}}=\frac{902}{902+3000}=23 \%
$$

And, the fault current:

$$
I_{f}=I_{N}=\frac{U_{e n}}{Z_{O \_ \text {int }}}=\frac{23 \% \times 10000}{\sqrt{3} \times 902}=1.5 \mathrm{~A}
$$

Only if the $\mathrm{u}_{\mathrm{en}}(\%)$ is bigger than $3 \mathrm{Uo}$ threshold value, fault alarm can be triggered. So that, the detection sensitivity is subject to neutral displacement during earth fault and resonance point value during normal condition. Given the system dissymmetry $\mathrm{k}=0.005$ and damping $\mathrm{d}=4 \%$, the resonance $\mathrm{U}_{\text {en.max }}$ can be decided:

$$
u_{\text {en.max }}(\%)=\frac{k}{d}=\frac{0.005}{0.04}=12.5 \%
$$

In other words, the threshold should be higher than $12.5 \%$, for instance, $13 \%$ threshold setting is possible to detect $6000 \mathrm{Ohm}$ high impedance faults that can be calculated as per eq.(8).

The way to increase detecting sensitivity is by enlarging $\mathrm{Z}_{\mathrm{O}_{-} \text {int, }}$ which can be known 
from chart 1 , Neutral displacement largely depends on the size of $\mathrm{Z}_{\mathrm{O}_{-} \text {int, the smaller }}$ zero sequence current calculated in bolted fault, the larger $\mathrm{Z}_{\mathrm{O}_{-} \text {int }}$ that can be attained.

\subsection{Capacitive Full-compensation Grounded System}

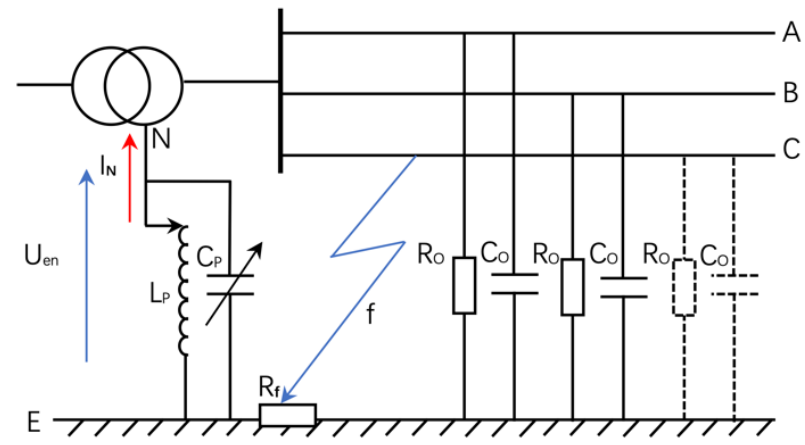

Figure 12: Earth fault in capacitive full-compensating grounded system

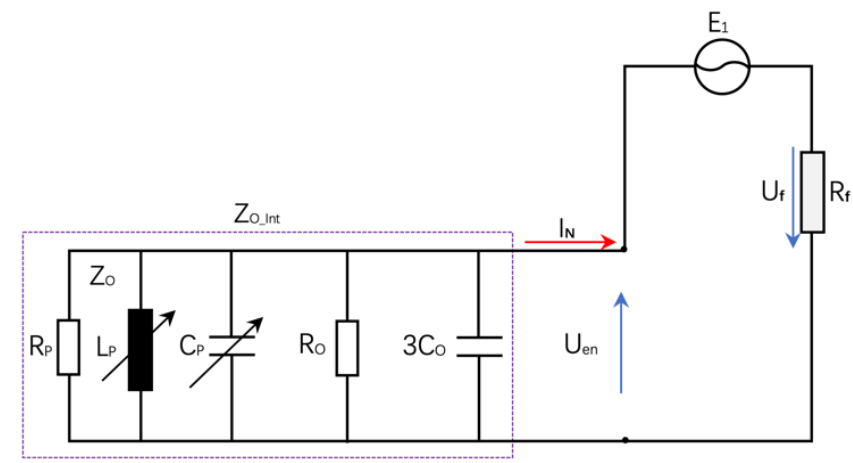

Figure 13: Equivalent zero sequence with capacitive full-compensating grounded system

Compared with Petersen coil, the capacitive Full-compensation grounding composed of Petersen coil and paralleled capacitor banks can get an even better and stronger zero sequence impedance $\mathrm{Z}_{\mathrm{O}_{-} \text {int, }}$ because the capacitive current is fully compensated i.e. $\mathrm{I}_{\mathrm{L}}=\mathrm{I}_{\mathrm{C}}$ as shown in figure 13 .

Detuning: $\mathrm{v}=0$

Damping: $\mathrm{d}=\mathrm{d}_{\mathrm{o}}$

With a bolted earth fault $\left(\mathrm{R}_{\mathrm{f}}=0\right)$ in $10 \mathrm{kV}$ grid, $\mathrm{I}_{\mathrm{C}}=100, \mathrm{~d}=\mathrm{d}_{\mathrm{o}}=4 \%, \mathrm{k}=0.005$, the current and voltage can be calculated below.

$$
I_{f}=I_{N}=I_{C} \cdot d_{o}=100 \times 0.04=4 A
$$

Where, the zero sequence current If $_{\mathrm{f}}$ now is fully determined by value of capacitive current with an normally unaltered damping.

Due to $\mathrm{R}_{\mathrm{f}}=0$, therefore:

$$
u_{e n}(\%)=100 \%
$$

So that, 


$$
Z_{O_{-} i n t}=\frac{U_{e n}}{I_{N}}=\frac{10000}{\sqrt{3} \times 4}=1443 \Omega
$$

The value of $\mathrm{Z}_{\mathrm{O} \_ \text {int }}$ is equivalent to that $1443 \mathrm{Ohm}$ high impedance fault can trigger a $50 \%$ neutral displacement, but imagining that threshold is $13 \%$, it could detect roughly $9600 \mathrm{Ohm}$ high impedance fault in $10 \mathrm{kV}$ grid. If it's a $22 \mathrm{kV}$ grid with the same conditions, $13 \%$ neutral displacement can reflect $21000 \mathrm{Ohm}$ high impedance fault which is not possible to be detected in $10 \mathrm{kV}$ grid, because neutral displacement is :

$$
u_{e n}(\%)=\frac{1443}{1443+21000}=6.4 \%<13 \%(\text { Threshold })
$$

It indicates that only if the threshold is below $6 \%$ is possible to detect it, which requires to balance the grid for smaller dissymmetry or lower damping by limiting the size of network. Normally dissymmetry is between $0.2 \%-0.5 \%$ for cable systems, but for overhead line could be $1 \%$ or more, thus the set of threshold often at a level of $20 \%$ to $30 \%$.

\subsection{Complete Current Compensation Grounded System}

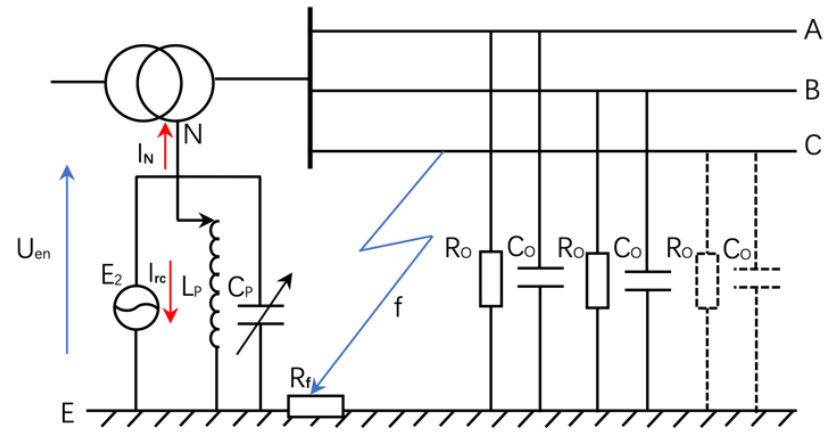

Figure 14: Earth fault in complete current compensation grounded system

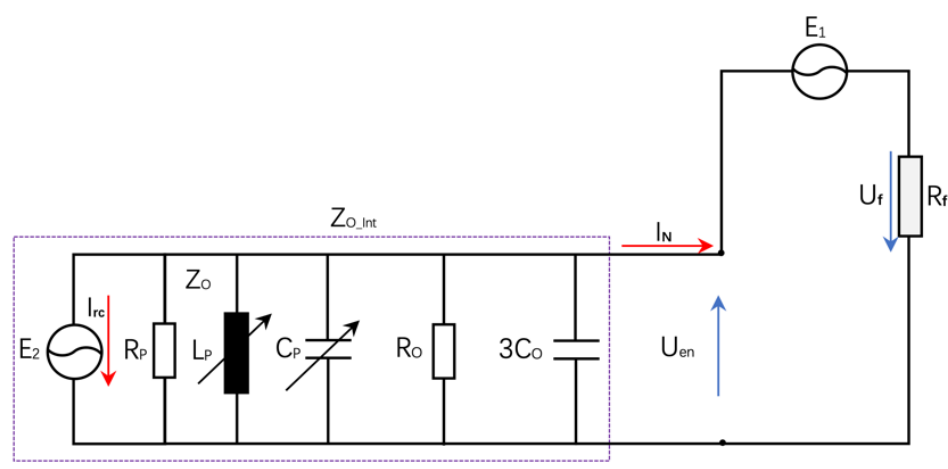

Figure 15: Equivalent zero sequence with complete current compensation grounded system

In capacitive full-compensation grounded system, there is still some resistive current $\mathrm{I}_{\mathrm{r}}$ resulted by damping $d_{o}$, i.e. $I_{r}=I_{C} * d_{o}$, what if this current is completely compensated by adding an extra power source E2 to output a current 180 degrees opposite to the current $\mathrm{I}_{\mathrm{r}}$ as shown in figure 15, which operates much like Petersen coil compensating capacitive current, then fault site goes to earth potential and the zero sequence 
impedance $\mathrm{Z}_{\mathrm{O} \_ \text {int }}$ is driven to infinity.

Due to $\mathrm{I}_{\mathrm{N}}=0$, with a bolted earth fault, neutral voltage displaces $100 \%$, and the zero sequence impedance $\mathrm{Z}_{\mathrm{O}_{-} \text {int }}$ can be calculated as:

$$
Z_{O_{-} \text {int }}=\lim _{I_{N \rightarrow 0}} \frac{U_{E N}}{I_{N}}=\infty
$$

So that, the neutral displacement under any high impedance fault will be:

$$
u(\%)=\lim _{Z_{O_{-i n t} \rightarrow \infty}} \frac{Z_{O_{-} \text {int }}}{\left(Z_{O_{-} \text {int }}+R_{f}\right)}=\lim _{Z_{o \_ \text {int } \rightarrow \infty}} \frac{1}{\left(1+\frac{R_{f}}{Z_{o \_ \text {int }}}\right)}=100 \%
$$

Consequently, fault current will steadily be Zero.

$$
I_{f}=I_{N}=\frac{U_{e n}}{Z_{O \_ \text {int }}}=0
$$

Whatever the threshold set to $30 \%$ or more, it doesn't matter to detect super high impedance earth faults that could be $100 \mathrm{kOhm}$ or higher, because neutral displacement always maintains $100 \%$ that can trigger any threshold, meanwhile, fault current at fault site is constantly zero which is safe.

\section{Mathematical Derivation of the Theory}

\subsection{Detection Sensitivity}

With the above calculations of different neutral groundings under one unified modelling, it can be concluded that the integral zero sequence impedance $Z_{\mathrm{o}_{-} \text {int }}$ closely relating to the capacity of neutral displacement is mainly determined by square root of $\left(\mathrm{v}^{2}+\mathrm{d}^{2}\right)$ in a certain size of grid, which is defined here as the factor of sensitivity,

$$
\sigma w=\sqrt{v^{2}+d^{2}}
$$

If the $\sigma \mathrm{W}$ increases, $\mathrm{Z}_{\mathrm{O} \_ \text {int }}$ and neutral displacement goes down proportionally according to eq.(5), (6) and (8), consequently the sensitivity is lower. As per the correlations between $\sigma \mathrm{w}$ and sensitivity, it can be derived a correlating formula:

\section{The First Equation:}

$$
S=\frac{1}{1+\sigma w}
$$

The sensitivity $\mathbf{S}$ here is defined as the degree of neutral voltage displacement caused by earth faults with identical fault impedance under different neutral grounding methods, which can be easily used to evaluate sensitivity of any neutral groundings relevant to neutral displacement.

Example: Assumed that a $10 \mathrm{kV}$ grid, $\mathrm{I}_{\mathrm{C}}=100 \mathrm{~A}, \mathrm{~d}_{\mathrm{o}}=4 \%, \mathrm{U}_{\mathrm{EN}}=\mathrm{U}_{\mathrm{ph}}=10000 / \sqrt{ } 3=5773 \mathrm{~V}$, $\sigma \mathrm{W}$ and $\mathrm{S}$ in each neutral grounding can be calculated according to the above-mentioned 
modelling. Table 1 is results of sensitivity ratio of neutral groundings by eq.(18).

\begin{tabular}{l|c|c|c|c}
\hline \multicolumn{1}{c|}{ Neutral Grounding Method } & V & d & $\boldsymbol{\sigma W}$ & S \\
\hline Complete Current Compensation & 0 & 0 & 0 & $\mathbf{1 0 0 \%}$ \\
\hline Capacitive full-compensation & 0 & 0.04 & 0.040 & $\mathbf{9 6 \%}$ \\
\hline Resonant Grounding & $5 \%$ & 0.04 & 0.064 & $\mathbf{9 4 \%}$ \\
\hline Ungrounded & $-100 \%$ & 0.04 & 1.000 & $\mathbf{5 0 \%}$ \\
\hline High Resistance Grounding & $-100 \%$ & 0.23 & 1.027 & $\mathbf{4 9 \%}$ \\
\hline Low Resistance Grounding & $-100 \%$ & 1.48 & 1.786 & $\mathbf{3 6 \%}$ \\
\hline Solid/Isolated Grounding & $-100 \%$ & $\infty$ & $\infty$ & $\mathbf{0 \%}$ \\
\hline
\end{tabular}

Table 1: Sensitivity ratio with different neutral grounding systems

The table 1 presents the ranking of sensitivity of neutral grounding which is in line with the actual situations. The value $\mathrm{S}$ is closely relevant to both neutral displacement and zero sequence current as described in 5.2 below.

\subsection{Neutral Voltage Displacement and Fault Current}

From eq.(18):

$$
\sigma w=\frac{1-S}{S}
$$

By using eq.(5), (6) and (8):

$$
Z_{O_{-} i n t}=\frac{U_{E N}}{I_{C} \cdot \sqrt{v^{2}+d^{2}}}=\frac{U_{E N}}{I_{C} \cdot \sigma w}=\frac{U_{E N} \cdot S}{I_{C} \cdot(1-S)}
$$

Therefore, neutral voltage displacement correlating with sensitivity $\mathrm{S}$ can be formulated as below:

$$
u_{e n}(\%)=\frac{S \cdot U_{E N}}{S \cdot U_{E N}+R_{f} \cdot I_{C} \cdot(1-S)}
$$

Also, fault Current can be formulated as below:

$$
I_{f}=\frac{U e n}{Z_{O_{-} i n t}}=\frac{U_{E N} \cdot I_{C} \cdot(1-S)}{S \cdot U_{E N}+R_{f} \cdot I_{C} \cdot(1-S)}
$$

With proper transformation of eq.(21) and (22),

$$
\begin{aligned}
& u_{e n}(\%)=\frac{1}{1+R_{f} \cdot \frac{1}{U_{E N}} \cdot \frac{I_{C}(1-S)}{S}} \\
& I_{f}=\frac{1}{\frac{S}{I_{C^{\circ}(1-S)}}+R_{f} \cdot \frac{1}{U_{E N}}}
\end{aligned}
$$


By extracting the common parts from eq.(23) and (24),

$$
K_{O}=\frac{S}{I_{C} \cdot(1-S)}
$$

Where, $\mathbf{K}_{\mathbf{O}}$ is a variable related to sensitivity $\operatorname{ratio}(\mathrm{S})$ and capacitive current $\left(\mathrm{I}_{\mathrm{C}}\right)$.

$$
\xi=\frac{1}{U_{E N}}
$$

Where, $\xi$ is a constant factor of fault impedance, it can be easily calculated with reciprocal of $U_{\mathrm{EN}}$ or phase voltage $\mathrm{U}_{\mathrm{ph}}$.

Eq. (23) and (24) can be equivalently further simplified and derived as:

\section{The Second Equation:}

$$
u_{e n}(\%)=\frac{K_{O}}{K_{O}+\xi \cdot R_{f}}
$$

With the second equation, the neutral displacement can be quantitatively calculated for any neutral groundings, meanwhile, it also can simply turn out the proportion of zero sequence voltage at fault site by:

$$
u_{f}(\%)=1-\frac{K_{O}}{K_{O}+\xi \cdot R_{f}}
$$

\section{The Third Equation:}

$$
I_{f}=\frac{1}{K_{O}+\xi \cdot R_{f}}
$$

Likewise, fault current can be quantitatively calculated by using the third equation.

The $1^{\text {st }}, 2^{\text {nd }}$ and $3^{\text {rd }}$ Equations give a unified theory for the first time in distribution field to fully integrate all neutral groundings for earth fault protection under one modelling, the most innovative discovery in this work is that all neutral groundings connected together with detuning(v), damping $(\mathrm{d})$ and capacitive current $\left(\mathrm{I}_{\mathrm{C}}\right)$. Although detuning is normally used in resonant grounding, it's also fit in other groundings by reasonably treating detuning value at negatively maximum position, i.e. $v=-100 \%$. Similarly, damping is barely mentioned expect for Petersen coil grounded system, whatsoever, it physically takes effect to influence the detection sensitivity with all neutral groundings, much like that working principle in resonance grounded system. Capacitive current is relevant to grid size, normally cable system contributes bigger capacitive current than overhead lines, from eq.(25) to (29), it can be known that larger $\mathrm{I}_{\mathrm{C}}$ reduces the variable $\mathrm{K}_{\mathrm{O}}$, neutral voltage $\mathrm{u}_{\mathrm{en}}(\%)$ consequently can be impacted with less displacement, and fault voltage and current will increases.

The unified theory also provides a simplified method to utilities, institutions and other electrical organizations to quantitatively evaluate any neutral grounding methods, in order to turn the extraordinary efforts in the field to be more efficient for higher power 
reliability and solution development etc..

Example: In a $10 \mathrm{kV}$ grid, by using the data $\mathbf{S}$ in table 1, assumed that earth fault with impedance $\mathrm{R}_{\mathrm{f}}$ from 0 to $30 \mathrm{kOhm}$, as per the Second and Third Equations, table 2 and 3 show the results of $\mathrm{u}_{\mathrm{en}}(\%)$ and $\mathrm{I}_{\mathrm{f}}$.

\begin{tabular}{|c|c|c|c|c|c|c|c|c|c|c|c|c|c|}
\hline \multirow{3}{*}{$\begin{array}{l}\text { Neutral } \\
\text { Grounding }\end{array}$} & \multirow{3}{*}{$\mathbf{S}$} & \multirow{3}{*}{ Ko } & \multirow{3}{*}{$\begin{array}{c}\xi \\
* 10^{-6}\end{array}$} & \multicolumn{10}{|c|}{ Fault Impedance in Ohms } \\
\hline & & & & 0.5 & 50 & 200 & 800 & 1500 & 3000 & 5000 & 8000 & 15000 & 30000 \\
\hline & & & & $\mathrm{U}_{\mathrm{en} 1 \%}$ & $\mathrm{U}_{\mathrm{en} 2} \%$ & $\mathrm{U}_{\mathrm{en} 3} \%$ & $\mathrm{U}_{\mathrm{en} 4 \%}$ & $\mathrm{U}_{\mathrm{en} 5 \%}$ & $\mathrm{U}_{\mathrm{en} 6} \%$ & $\mathbf{U}_{\mathrm{en} 7 \%}$ & $\mathbf{U}_{\mathrm{en} 8} \%$ & $\mathrm{U}_{\mathrm{en} 9 \%}$ & $\mathbf{U}_{\mathrm{en} 10 \%}$ \\
\hline Solid G. & $0 \%$ & 0 & 173 & $0 \%$ & $0 \%$ & $0 \%$ & $0 \%$ & $0 \%$ & $0 \%$ & $0 \%$ & $0 \%$ & $0 \%$ & $0 \%$ \\
\hline Low Resist. & $36 \%$ & 0.0056 & 173 & $98 \%$ & $39 \%$ & $14 \%$ & $4 \%$ & $2.1 \%$ & $1.1 \%$ & $0.6 \%$ & $0.4 \%$ & $0.2 \%$ & $0.1 \%$ \\
\hline High Resist. & $49 \%$ & 0.0096 & 173 & $99 \%$ & $53 \%$ & $22 \%$ & $6 \%$ & $3.6 \%$ & $1.8 \%$ & $1.1 \%$ & $0.7 \%$ & $0.4 \%$ & $0.2 \%$ \\
\hline Ungrounded & $50 \%$ & 0.0100 & 173 & $99 \%$ & $54 \%$ & $22 \%$ & $7 \%$ & $3.7 \%$ & $1.9 \%$ & $1.1 \%$ & $0.7 \%$ & $0.4 \%$ & $0.2 \%$ \\
\hline Resonance & $94 \%$ & 0.1567 & 173 & $100 \%$ & $95 \%$ & $82 \%$ & $53 \%$ & $37.6 \%$ & $23.2 \%$ & $15.3 \%$ & $10.2 \%$ & $5.7 \%$ & $2.9 \%$ \\
\hline $\begin{array}{l}\text { Capacitive } \\
\text { Comp. }\end{array}$ & $96 \%$ & 0.24 & 173 & $100 \%$ & $97 \%$ & $87 \%$ & $63 \%$ & $48.0 \%$ & $31.6 \%$ & $21.7 \%$ & $14.8 \%$ & $8.5 \%$ & $4.4 \%$ \\
\hline $\begin{array}{l}\text { Complete } \\
\text { Comp. }\end{array}$ & $100 \%$ & $\infty$ & 173 & $100 \%$ & $100 \%$ & $100 \%$ & $100 \%$ & $100 \%$ & $100 \%$ & $100 \%$ & $100 \%$ & $100 \%$ & $100 \%$ \\
\hline
\end{tabular}

Table 2: Neutral displacement under fault impedance from 0 to $30 \mathrm{kOhm}$ with different grounding methods.

Chart 2 below contains but not limited to the information in table 2 to offer a visual interpretation on relations between neutral displacement and fault impedance with difference grounding methods.

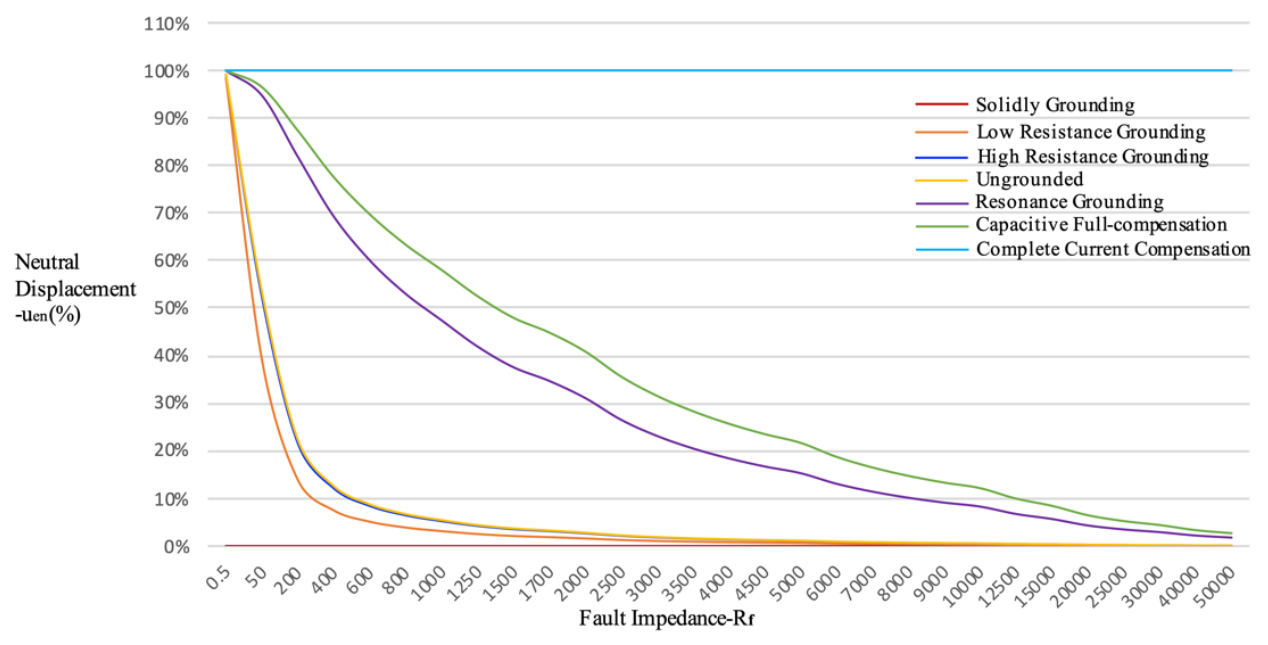

Chart 2: Relations between neutral displacement and fault impedance with various neutral groundings in $10 \mathrm{kV}$ grid

The chart 2 shows that all neutral groundings except Solid Grounding give a full displacement in bolted faults $\left(\mathrm{R}_{\mathrm{f}}\right.$ close to zero), and all but Complete Current Compensation eventually are pulled back to $0 \%$ neutral displacement when earth faults with super high fault impedance.

Solid Grounding with a steady $0 \%$ displacement and oppositely Complete Current Grounding with a strong $100 \%$ displacement whatever the fault impedance is. But neutral displacement for Low Resistance Grounding, High Resistance Grounding and ungrounded systems is steeply dropped down with fault impedance from 0.5 to 400 Ohms, which can be considered as a weakened character on "voltage splitting". 
Apparently, Peterson Coil and capacitive full-compensation both present strong integral zero sequence impedance ( $\mathrm{Z}_{\mathrm{O}_{-} \text {int }}$ ) to aggressively occupy as much zero sequence voltage as possible with neutral displacement gently declining as the fault impedance increases in chart 2.

\begin{tabular}{|c|c|c|c|c|c|c|c|c|c|c|c|c|c|}
\hline \multirow{3}{*}{$\begin{array}{c}\text { Neutral } \\
\text { Grounding }\end{array}$} & \multirow{3}{*}{$\mathbf{S}$} & \multirow{3}{*}{ Ko } & \multirow{3}{*}{$\begin{array}{c}\xi \\
* 10^{-6}\end{array}$} & \multicolumn{10}{|c|}{ Fault Impedance in Ohms } \\
\hline & & & & 0.5 & 50 & 200 & 800 & 1500 & 3000 & 5000 & 8000 & 15000 & 30000 \\
\hline & & & & $I_{f} 1(A)$ & $\mathrm{I}_{\mathrm{f}} 2(\mathrm{~A})$ & $\mathrm{I}_{\mathrm{f}} 3(\mathrm{~A})$ & $I_{f} 4(A)$ & $I_{f} 5(A)$ & $\mathrm{I}_{\mathrm{f}} 6(\mathrm{~A})$ & If7 (A) & $\mathrm{I}_{\mathrm{f}} 8(\mathrm{~A})$ & $\mathrm{I}_{\mathrm{f}} 9(\mathrm{~A})$ & $\mathrm{I}_{\mathrm{f}} \mathbf{1 0}(\mathrm{A})$ \\
\hline Solidly & $0 \%$ & 0 & 173 & 11547 & 115.47 & 28.87 & 7.22 & 3.85 & 1.92 & 1.15 & 0.72 & 0.38 & 0.19 \\
\hline Low resist. & $36 \%$ & 0.0056 & 173 & 175.08 & 70.00 & 24.83 & 6.94 & 3.77 & 1.90 & 1.15 & 0.72 & 0.38 & 0.19 \\
\hline High resist. & $49 \%$ & 0.0096 & 173 & 103.15 & 54.74 & 22.60 & 6.75 & 3.71 & 1.89 & 1.14 & 0.72 & 0.38 & 0.19 \\
\hline Ungrounded & $50 \%$ & 0.0100 & 173 & 99.14 & 53.59 & 22.40 & 6.73 & 3.71 & 1.89 & 1.14 & 0.72 & 0.38 & 0.19 \\
\hline Resonance & $94 \%$ & 0.1567 & 173 & 6.38 & 6.05 & 5.23 & 3.39 & 2.40 & 1.48 & 0.98 & 0.65 & 0.36 & 0.19 \\
\hline $\begin{array}{l}\text { Capacitive } \\
\text { comp. }\end{array}$ & $96 \%$ & 0.24 & 173 & 4.17 & 4.02 & 3.64 & 2.64 & 2.00 & 1.32 & 0.90 & 0.62 & 0.35 & 0.18 \\
\hline $\begin{array}{l}\text { Complete } \\
\text { Comp. }\end{array}$ & $100 \%$ & $\infty$ & 173 & 0.00 & 0.00 & 0.00 & 0.00 & 0.00 & 0.00 & 0.00 & 0.00 & 0.00 & 0.00 \\
\hline
\end{tabular}

Table 3: Fault current under fault impedance from 0 to $30 \mathrm{kOhm}$ with different grounding methods.

Chart 3 below contains but not limited to the information in table 3 to provide a visual interpretation on relations between fault current and fault impedance with difference grounding methods.

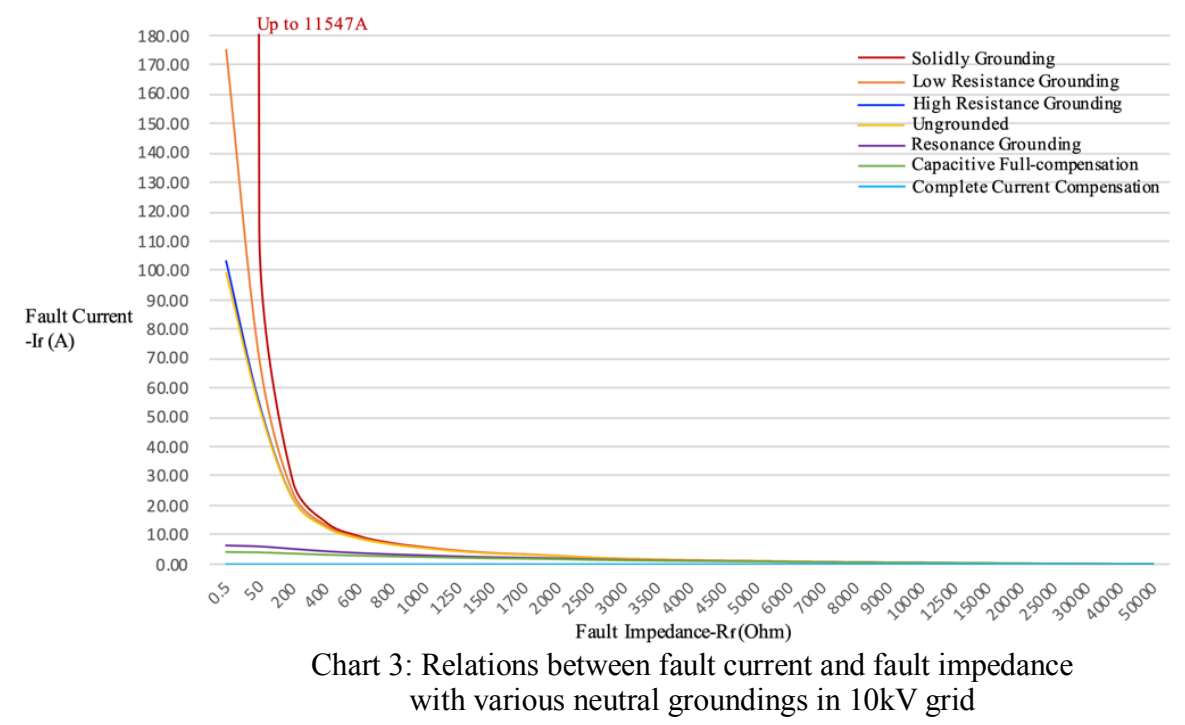

The chart 3 shows that zero sequence current sharply declines from extremely high level to $10-15 \mathrm{~A}$ with fault impedance from 0.5 to $400 \mathrm{Ohm}$ in Solid grounding, Low resistance, High resistance and Ungrounded systems. Most likely over-current protection is not able to detect the fault due to low current flow, let alone the fault impedance beyond $400 \mathrm{Ohm}$.

In contrast, Resonant grounding and Capacitive Full-compensation grounding that both reflect an extraordinary efficiency on limiting initial fault current in a super low level, which gives opportunity to keep the fault site relatively safe to avoid human injury or death, and fire ignition on flammable objects like vegetation, residential house etc. 
By far, Complete Current Compensation grounding is the ultimate method with the highest detection sensitivity which makes the neutral displacement always $100 \%$ and fault current at zero all the time under any low or high impedance earth fault. The fault site is absolutely safe and secured.

Particularly, in Solidly grounded system, single phase earth fault turns to single phase to ground short circuit with terribly high fault current flow during a bolted earth fault as shown in Chart 3, the current value could be higher than 10kA if the fault impedance is low enough, however, the current steps down rapidly even in relatively very low impedance fault compared with other grounding systems, it can be imagined that solid grounding could be blinded on slightly high impedance fault, no tripping could make the fault site hazardous.

\section{Conclusions}

This paper proposes a pioneering modelling of neutral groundings in power distribution that expressed in Three Equations as core of the unified theory which is applicable to any neutral grounding systems subject to zero sequence voltage or/and zero sequence current, that can be conveniently utilized to calculate and evaluate neutral grounding's character, sensitivity, capacity of neutral displacement, residual current limitation and further analysis according to various operating conditions in distribution grids.

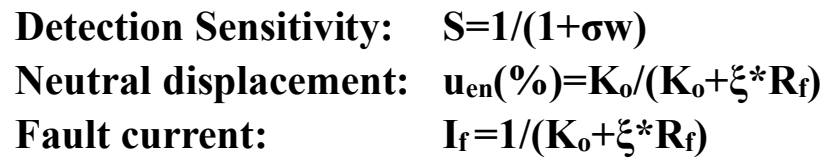




\section{References}

[1]. T. Marxsen. "New technology to cut Victoria's powerline fire risk". Marxsen Consulting Pty Ltd.. Conference paper, 2016.

[2]. "Electric Incident Report Filed with CPUC in Response to Kincade Fire". Pacific Gas and Electric Company, released on 24 Oct. 2019. Source available at:

https://www.pge.com/en/about/newsroom/newsdetails/index.page?title=20191024_ele ctric_incident_report_filed_with_cpuc_in_response_to_kincade_fire

[3]. "Technical guidelines for distribution network". State Grid Corporation. Q/GDW 10370 - 2016, published on 24 Mar. 2017

[4]. David Flores. "Handling of Ground Fault in Distribution Networks". Norwegian University of Science and Technology Department of Electric Power Engineering, 2009.

[5]. Douglas P. S. Gomes, Cagil Ozansoy. "High-Impedance Faults in Power Distribution Systems: A Narrative of the Field's Developments". Victoria University Melbourne, 2020. 